\title{
Correction to: The FreeD module for the Lokomat facilitates a physiological movement pattern in healthy people - a proof of concept study
}

Tabea Aurich-Schuler ${ }^{1,2^{*}+}$, Anja Gut ${ }^{1,3+}$ and Rob Labruyère ${ }^{1,2}$

\section{Correction to: J Neuroeng Rehabil https://doi.org/10.1186/s12984-019-0496-x}

The original article [1] contains an error whereby the legends of Figs. 3 and 4 are erroneously swapped. As such, the correct configuration of these legends can be seen in the same figures below instead.

\begin{abstract}
Author details
'Rehabilitation Center Affoltern am Albis, Children's University Hospital Zurich, Mühlebergstrasse 104, CH-8910 Affoltern am Albis, Switzerland. ${ }^{2}$ Children's Research Center, Children's University Hospital Zurich, Steinwiesstrasse 75, CH-8032 Zurich, Switzerland. ${ }^{3}$ Department of Health Sciences and Technology, ETH Zurich, Vladimir-Prelog-Weg 1-5/10, CH-8093 Zürich, Switzerland.
\end{abstract}

Received: 28 May 2019 Accepted: 28 May 2019

Published online: 11 June 2019

\section{Reference}

1. Aurich-Schuler T, Gut A, Labruyère R. The FreeD module for the Lokomat facilitates a physiological movement pattern in healthy people - a proof of concept study. J Neuroeng Rehabil. 2019;16(26). https://doi.org/10.1186/ s12984-019-0496-x.

\footnotetext{
* Correspondence: tabea.aurich@kispi.uzh.ch

${ }^{\dagger}$ Tabea Aurich-Schuler and Anja Gut contributed equally to this work.

'Rehabilitation Center Affoltern am Albis, Children's University Hospital Zurich, Mühlebergstrasse 104, CH-8910 Affoltern am Albis, Switzerland

${ }^{2}$ Children's Research Center, Children's University Hospital Zurich,

Steinwiesstrasse 75, CH-8032 Zurich, Switzerland

Full list of author information is available at the end of the article
}

(c) The Author(s). 2019 Open Access This article is distributed under the terms of the Creative Commons Attribution 4.0 International License (http://creativecommons.org/licenses/by/4.0/), which permits unrestricted use, distribution, and reproduction in any medium, provided you give appropriate credit to the original author(s) and the source, provide a link to the Creative Commons license, and indicate if changes were made. The Creative Commons Public Domain Dedication waiver (http://creativecommons.org/publicdomain/zero/1.0/) applies to the data made available in this article, unless otherwise stated. 


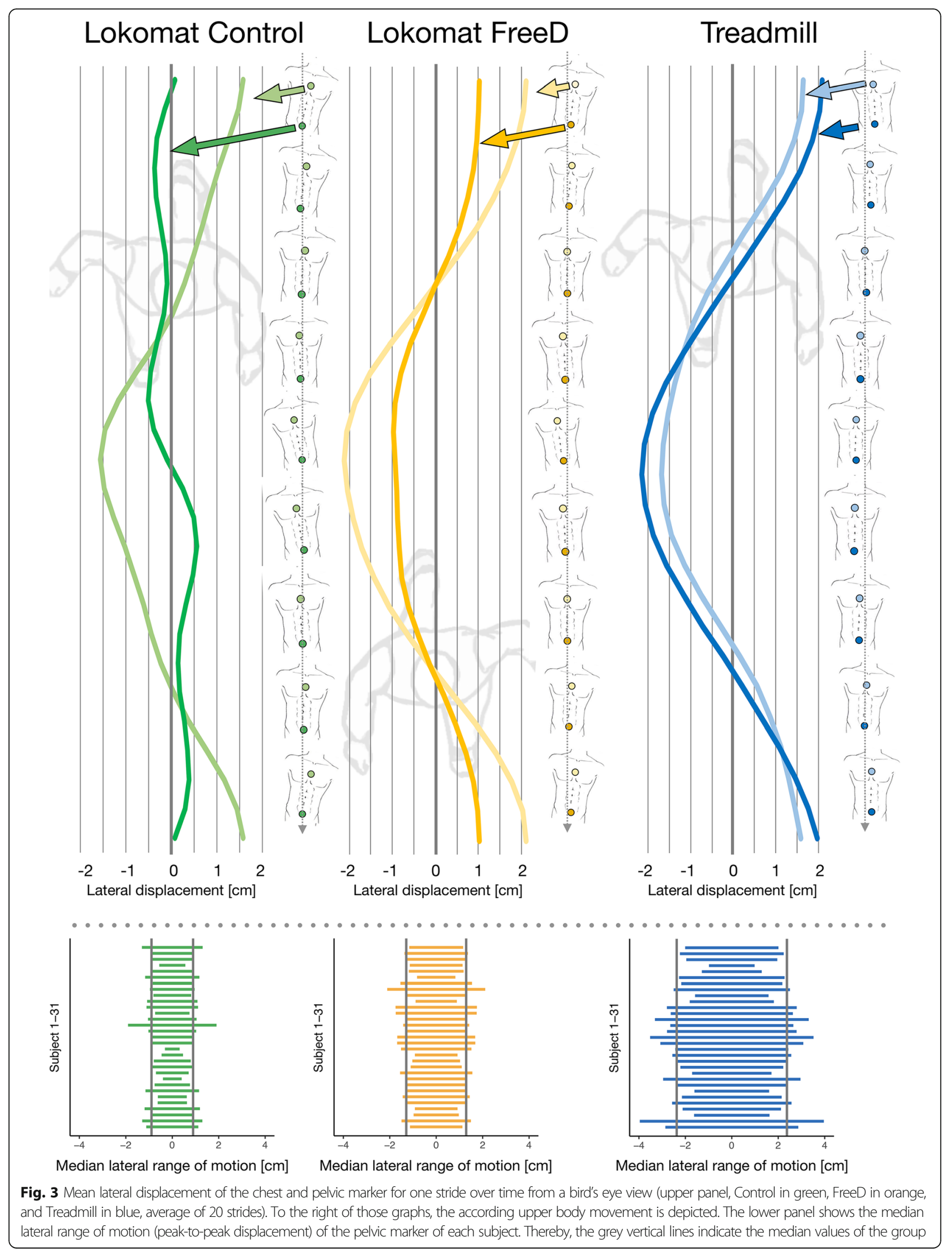




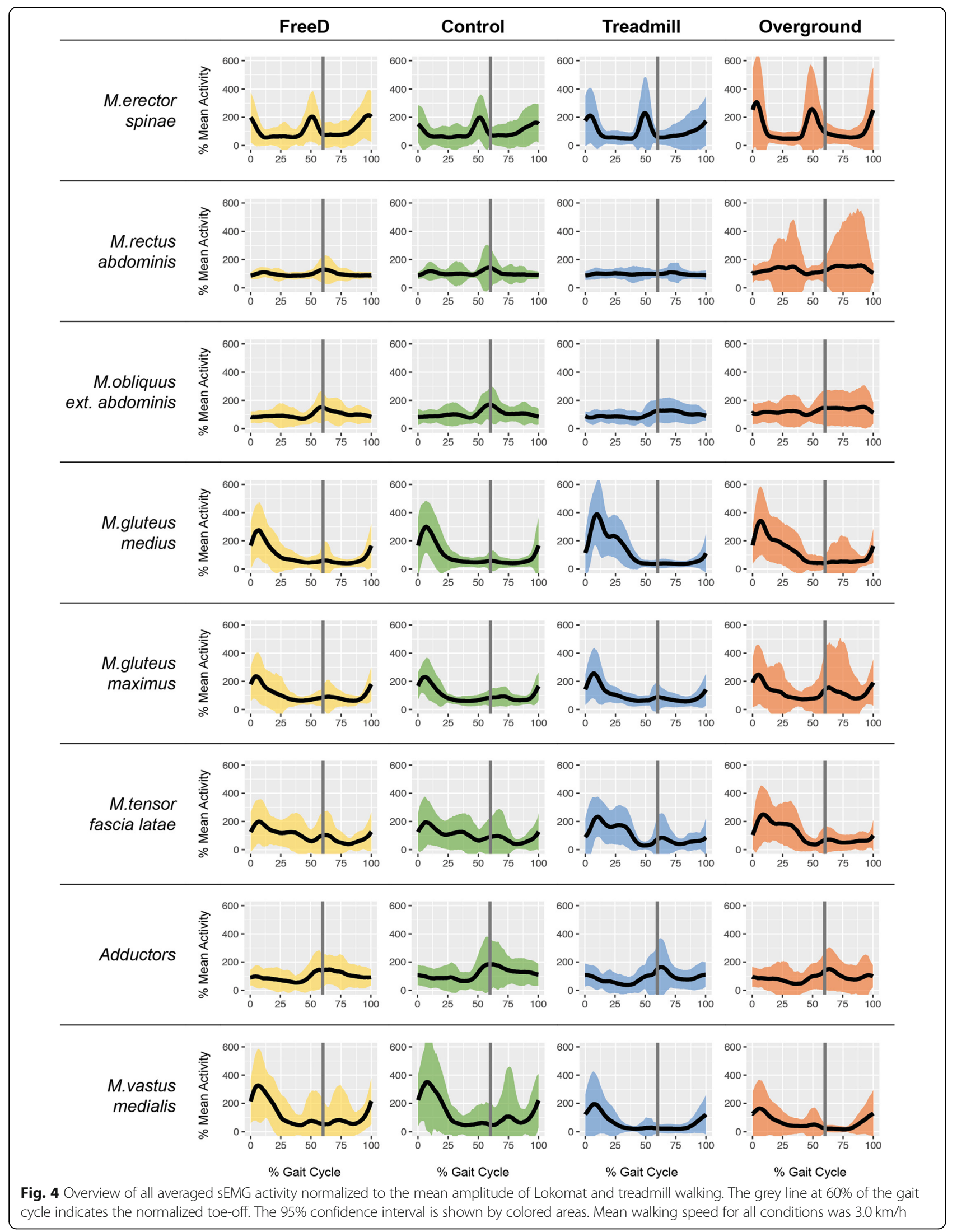

